\title{
The dose-response of nitrous oxide in postoperative nausea in patients undergoing gynecologic laparoscopic surgery: a preliminary study.
}

Boris Mraovic

Thomas Jefferson University

Tatjana Simurina

General Hospital Zadar, Zadar, Croatia

Zdenko Sonicki

School of Public Health Andrija Štampar, University of Zagreb, Zagreb, Croatia

Neven Skitarelic

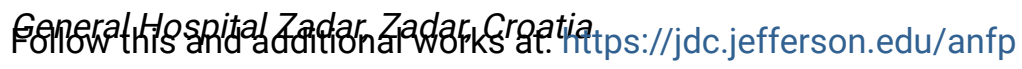

Trgat. \&ane Anesthesiology Commons, and the Cardiology Commons puketuriserkiknodisationter access to this document benefits you

\section{Recommended Citation}

Mraovic, Boris; Simurina, Tatjana; Sonicki, Zdenko; Skitarelic, Neven; and Gan, Tong J., "The dose-response of nitrous oxide in postoperative nausea in patients undergoing gynecologic laparoscopic surgery: a preliminary study." (2008). Department of Anesthesiology Faculty Papers. Paper 3.

https://jdc.jefferson.edu/anfp/3

This Article is brought to you for free and open access by the Jefferson Digital Commons. The Jefferson Digital Commons is a service of Thomas Jefferson University's Center for Teaching and Learning (CTL). The Commons is a showcase for Jefferson books and journals, peer-reviewed scholarly publications, unique historical collections from the University archives, and teaching tools. The Jefferson Digital Commons allows researchers and interested readers anywhere in the world to learn about and keep up to date with Jefferson scholarship. This article has been accepted for inclusion in Department of Anesthesiology Faculty Papers by an authorized administrator of the Jefferson Digital Commons. For more information, please contact: JeffersonDigitalCommons@jefferson.edu. 
As submitted to:

Anesthesia and Analgesia

and later published as:

"The dose-response of nitrous oxide in postoperative nausea in patients undergoing gynecologic laparoscopic surgery: A preliminary study" Anesthesia and Analgesia

Volume 107, Issue 3, September 2008, Pages 818-823

DOI: 10.1213/ane.0b013e318181f4aa

\begin{abstract}
Dose-Response of Nitrous Oxide in Postoperative Nausea in Patients undergoing Gynecologic Laparoscopic Surgery - A Preliminary Study.
\end{abstract}

Short title: Dose-Response of nitrous oxide in PONV

Boris Mraovic, M.D.,\# Tatjana Šimurina, M.D., M.Sc., ${ }^{*}$ Zdenko Sonicki, M.D., Ph.D.,‡ Neven Skitarelić, M.D., Ph.D.,§ Tong J Gan, M.D.,凹

\# Assistant Professor of Anesthesiology, Department of Anesthesiology, Thomas Jefferson University, Philadelphia, PA, USA

* Staff Anesthesiologist, Department of Anesthesiology and ICU, General Hospital Zadar, Zadar, 


\section{Croatia}

\$ Assistant Professor of Biostatistics, Department of Medical Statistics, Epidemiology and Medical Informatics, School of Public Health “Andrija Štampar”, Faculty of Medicine, University of Zagreb, Zagreb, Croatia

$\S$ Associate Professor of Otorhinolaryngology, ENT Department, General Hospital Zadar, Zadar, Croatia

II Professor of Anesthesiology, Department of Anesthesiology, Duke University Medical Center, Durham, NC, USA

\section{Conflict of Interest:}

Tong J Gan, M.D.: Current and previous research grant support and honoraria from Baxter, Merck, MGi and Roche, Inc. None of the above companies manufacture or market nitrous oxide.

The data from the study were presented at the ASA meeting in Chicago, October 2006 and 2nd World Congress of Minimally Invasive Gynecological Surgery, Dubrovnik, Croatia, June 2006.

This work was partly supported by the Croatian Ministry of Science, Education and Sport; research project "Predictive Models in Health Care" No. 108-0982560-0257.

\section{Corresponding author:}

Boris Mraovic, M.D.

Assistant Professor of Anesthesiology,

Department of Anesthesiology,

Thomas Jefferson University,

11 South $11^{\text {th }}$ Street Suite G8490

Philadelphia, PA 19107, USA 
Pone: 1-215-955-6161

Fax: 1-215-955-0677

Email: Boris.Mraovic@jefferson.edu

\section{Reprints:}

Boris Mraovic, M.D.

Assistant Professor of Anesthesiology,

Department of Anesthesiology,

Thomas Jefferson University,

11 South $11^{\text {th }}$ Street Suite G8490

Philadelphia, PA 19107, USA 


\section{Implications Statement:}

We demonstrate that nitrous oxide $\left(\mathrm{N}_{2} \mathrm{O}\right)$ increases the incidence of postoperative nausea after laparoscopic gynecologic surgery. The preliminary findings indicate that $\mathrm{N}_{2} \mathrm{O}$ may increase PONV in dose dependant fashion. High concentration of $\mathrm{N}_{2} \mathrm{O}$ in this clinical setting is not recommended. 


\section{Abstract:}

Background: Whether nitrous oxide $\left(\mathrm{N}_{2} \mathrm{O}\right)$ increases incidence of postoperative nausea and vomiting (PONV) after laparoscopic gynecologic surgery is still controversial. This uncertainty may be due to the administration of different concentrations of inspired $\mathrm{N}_{2} \mathrm{O}$. We investigated if $\mathrm{N}_{2} \mathrm{O}$ results in a dose response increase in PONV.

Methods: Patients undergoing gynecologic laparoscopic surgery were randomized to receive $30 \%$ oxygen with air $(\mathrm{G} 0, \mathrm{n}=46), 50 \% \mathrm{~N}_{2} \mathrm{O}$ with oxygen $(\mathrm{G} 50, \mathrm{n}=46)$ and $70 \% \mathrm{~N}_{2} \mathrm{O}$ with oxygen $(\mathrm{G} 70, \mathrm{n}=45)$. A standardized general anesthetic was used with no PONV prophylaxis. Known risk factors for PONV were controlled. Metoclopramide was used as a rescue antiemetic. Incidence of nausea, vomiting, use of rescue antiemetic and pain VAS score were measured at 2 and 24 hours postoperatively.

Results: Patient demographics were comparable and there were no differences among groups with regards to factors that may influence PONV. Incidence of PONV at 24 hours was $33 \%$ (15/46) in G0 versus 46\% (21/46) in G50 versus 62\% (28/45) in G70 (p=0.018). Subgroup analysis revealed a difference between $\mathrm{G} 0$ vs $\mathrm{G} 70(\mathrm{p}=0.018)$, but no significant difference between G0 vs G50 and G50 vs G70. The incidence of nausea showed a similar difference $(\mathrm{G} 0=26 \%, \mathrm{G} 50=35 \%$ and $\mathrm{G} 70=56 \% ; \mathrm{p}=0.012)$, but the incidence of vomiting was not different between the groups, although there was a trend $(\mathrm{G} 0=28 \%, \mathrm{G} 50=35 \%$ and $\mathrm{G} 70=42 \%$; $\mathrm{p}=0.377)$. Severity of nausea (measured by VAS $100 \mathrm{~mm}$ ) was significantly increased with increasing $\mathrm{N}_{2} \mathrm{O}$ concentration $(\mathrm{G} 0=10.9, \mathrm{G} 50=12.7$ and $\mathrm{G} 70=20.5 ; \mathrm{p}=0.027)$. The worst VAS score during 24 hours was used for the analysis. There was no difference in the use of a rescue antiemetic. Pain VAS scores and opioids consumption were not different among groups (at $2 \mathrm{~h}$ and $24 \mathrm{~h}$ after surgery).

Conclusion: $\mathrm{N}_{2} \mathrm{O}$ increases the incidence of postoperative nausea after gynecologic 
laparoscopic surgery. This preliminary findings indicate that $\mathrm{N}_{2} \mathrm{O}$ may increase PONV in dose dependent fashion. A study with sample size of $>400$ patients in each group would be necessary to demonstrate a statistically significant difference among each of these three groups. We do not recommend using high concentration of $\mathrm{N}_{2} \mathrm{O}$ in this clinical setting.

Word Count: 342 


\section{Introduction:}

Postoperative nausea and vomiting (PONV) are common complications after gynecologic laparoscopic surgery. In the absence of prophylactic antiemetics the incidence of PONV may be as high as $40 \%-77 \%$ (1-4). The administration of prophylactic antiemetics, either alone or in combination have been shown to reduce this incidence. However, the routine administration of antiemetics increases costs and side effects $(5,6)$. Reducing baseline risk has been recommended as an effective strategy for reducing PONV, including using specific anesthetic techniques that minimize the risk of PONV $(7,8)$.

Nitrous oxide $\left(\mathrm{N}_{2} \mathrm{O}\right)$ has analgesic and sedative properties (9), but may potentially increase the incidence of PONV $(10,11) . \mathrm{N}_{2} \mathrm{O}$ might increase incidence of PONV by several potential mechanisms: 1) increase in middle ear pressure $(12,13) ; 2)$ bowel distension which is controversial (14-16). A recent meta-analysis revealed that each additional hour of anesthesia using $\mathrm{N}_{2} \mathrm{O}$ doubles the risk of bowel distension (odds ratio 2.09; 95\% CI 1.27-3.59) compared with anesthesia using air/oxygen (14); 3) activation of the dopaminergic system in the chemoreceptor trigger zone (17); and 4) interaction with opioid receptors (18).

The evidence on PONV after $\mathrm{N}_{2} \mathrm{O}$ /volatile anesthetic (enflurane or isoflurane) in gynecologic laparoscopic surgery is controversial. $\mathrm{N}_{2} \mathrm{O}$ has been demonstrated to increase the incidence of PONV in some studies $(10,11,19-22)$ but not others $(23-26)$. Most of the studies on the influence of $\mathrm{N}_{2} \mathrm{O}$ on PONV used $60 \%$ to $70 \%$ inspiratory concentration $(\mathrm{FI})$ of $\mathrm{N}_{2} \mathrm{O}$. It is not clear if limiting $\mathrm{N}_{2} \mathrm{O}$ to a lower concentration decreases the risk of PONV. We postulate that inspiratory concentration of $\mathrm{N}_{2} \mathrm{O}$ has a dose/response relationship to the incidence of PONV. Our experimental hypothesis is that the incidence of PONV would increase as inspiratory $\mathrm{N}_{2} \mathrm{O}$ concentration increases from $50 \%$ and $70 \%$ when compared to air/oxygen (FI $\mathrm{O}_{2} 30 \%$ ) as a control group in gynecologic laparoscopic surgery under general anesthesia. 


\section{Methods:}

After Institutional Review Board approval, written informed consent was obtained in 150 ASA PS I and II patients, between 19 to 75 years old, undergoing elective laparoscopic gynecological surgery (removal of the ovarian tumors and cysts, myomectomy, laparoscopic assisted vaginal hysterectomy and infertility surgery). The exclusion criteria were obesity (BMI $>33 \mathrm{~kg} / \mathrm{m}^{2}$ ), pregnancy, breast feeding, known hypersensitivity to drugs used in the study protocol, use of antiemetics, psychotropic drugs and steroids within $72 \mathrm{~h}$ before surgery. Patients with known comorbidities that may increase the incidence of PONV were also excluded, i.e. diseases which impaired gastric motility (diabetes mellitus, chronic cholecystitis, gastric and intestinal disease, neuromuscular disorders, neuropathies and liver dysfunction), vestibular disease, history of migraine headache, central nervous system injury, renal impairment, irregular menstrual cycle (duration of $<21$ or $>35$ days and/or variations between cycles $>4$ days), alcoholism and opioid addiction.

As per standard practice in the hospital, patients received $7.5 \mathrm{mg}$ of midazolam PO $1 \mathrm{~h}$ before the surgery with no prophylactic antiemetics. Standard monitoring was applied including electrocardiography, noninvasive blood pressure, pulse oximetry and capnography.

After induction of anesthesia with thiopental $5 \mathrm{mg} / \mathrm{kg}$ and fentanyl $1-2 \mu \mathrm{g} / \mathrm{kg}$, patients were manually ventilated via face mask with oxygen. Endotracheal intubation was facilitated with vecuronium $0.1 \mathrm{mg} / \mathrm{kg}$ IV. Patients were randomized by computer-generated random numbers to receive air and oxygen, FI $\mathrm{O}_{2} 30 \%$ (group G0), 50\% $\mathrm{N}_{2} \mathrm{O}$ and oxygen (group G50) or $70 \% \mathrm{~N}_{2} \mathrm{O}$ and oxygen (group G70). Anesthesia was maintained with sevoflurane (end tidal concentration $\sim 1$ minimum alveolar concentration [MAC]) and supplemental bolus doses of fentanyl IV ( $1 \mu \mathrm{g} / \mathrm{kg})$ to keep heart rate and blood pressure within $20 \%$ of baseline values and additional vecuronium was administered to maintain a one or two twitches on the train-of-four 
monitor. All patients received $10 \mathrm{ml} / \mathrm{kg}$ of crystalloids intraoperatively. Insertion of a nasogastric tube and gastric suction was not used. Neuromuscular blockade was antagonized with neostigmine $2.5 \mathrm{mg}$ and atropine $1 \mathrm{mg} \mathrm{IV}$.

Postoperatively, patients received $1000 \mathrm{ml}(5 \mathrm{ml} / \mathrm{kg} / \mathrm{h})$ of crystalloids. The incidence of postoperative nausea, vomiting and the use of rescue antiemetic were collected at 2 and 24 hours after surgery. Severity of postoperative nausea and pain were evaluated using a $100 \mathrm{~mm}$ visual analogue scale (VAS) during the first 24 hours postoperatively (VAS $0=$ no pain/nausea, $100=$ maximal pain/nausea). A nausea VAS score was measured for each episode, but the worst score during the early and the late period was used for statistical evaluation. Patients who experienced at least one episode of nausea, vomiting or retching or any combination of these occurred during 24 hours postoperatively were considered to have had PONV . POV was defined as at least one episode of vomiting or retching that occurred within 24 hours postoperatively. PONV was defined as early (within first 2 hours) or late (2 to 24 hours postop). Clinical nurses specifically trained for the study collected the data and were blinded to the anesthesia technique used and randomization. Pain VAS score and total amount of opioids were recorded at 2 hours and at 24 hours postoperatively. Metoclopramide $10 \mathrm{mg}$ IV was used as the rescue antiemetic. This was the standard clinical practice in the hospital. The administration of rescue antiemetic was based on the following criteria: patients who had two or more episodes of vomiting or retching within a period of $30 \mathrm{~min}$, nausea lasting more than $15 \mathrm{~min}$ or nausea VAS score $50 \mathrm{~mm}$ or greater, or when a patient requested treatment. Diclofenac 75 mg IM was given immediately after surgery and if needed 12 hours later. For severe pain (VAS $>40 \mathrm{~mm}$ ) meperidine $25 \mathrm{mg}$ up to $100 \mathrm{mg}$ IV was used. All patients remained in the hospital for at least for 24 hours, as was our standard practice for laparoscopic gynecological surgery.

Statistical analysis 
Calculation of sample size was based on preliminary data collected at General Hospital Zadar, Zadar, Croatia (27). A total of 45 patients per group would be sufficient to demonstrate a reduction of PONV by $20 \%$ from G70 to G50 and by $20 \%$ from G50 to G0 with a power of 0.8 and $\alpha<0.05$. The expected incidence of PONV at 24 hours was for G0=30\%, G50=50\% and $\mathrm{G} 70=70 \%$. The data were analyzed using statistical program SAS 8.2. Quantitative values were compared using Kruskal-Wallis test and Mann-Whitney U test with correction for multiple comparisons between the groups. Categorical data were analyzed by Pearson Chi-Square test or Fisher's exact test with correction for multiple comparisons as appropriate. Data were expressed as number or percentages and mean \pm SD. A $p$ value of $<0.05$ was considered statistically significant. 


\section{Results:}

One hundred thirty seven of 150 patients completed the study (G0=46, G50=46, $\mathrm{G} 70=45)$. A total of 13 patients were excluded from the analysis. Four patients were excluded in G0: one patient was treated with corticosteroids for urticaria at induction of anesthesia, one patient had an anesthesia time less than 30 min, 2 patients had a protocol violation; 4 patients were excluded in G50: conversion to laparotomy, anesthesia time less than $30 \mathrm{~min}$ and 2 patients had a protocol violation; 5 patients were excluded in G70: 2 patients' surgery was converted to laparotomy, 1 patient each had severe hypotension after induction which lasted more than 5 minutes, acute coronary syndrome postoperatively and anesthesia time less than 30 $\min$.

There was no difference among groups regarding age, weight, height, BMI, ASA physical status, smoking status, history of motion sickness and/or PONV, phase of menstrual cycle, thiopental dose, duration of anesthesia and surgery and type of surgery (Table 1),

There was an overall difference in the incidence of PONV for 24 hours after surgery between the groups ( $\mathrm{p}=0.018)$ (Table 2$)$. G0 was significantly different vs $\mathrm{G} 70(\mathrm{p}=0.018)$ but no difference was noted between G0 vs G50 ( $\mathrm{p}=0.855$ ) or G50 vs G70 ( $\mathrm{p}=0.426$ ) (Table 2). Although there was a trend towards an increase in the incidence of early PONV (two hours postoperatively) and late postoperative period (2-24h) with increasing $\mathrm{N}_{2} \mathrm{O}$ concentration this did not reach statistical significance, $\mathrm{p}=0.071$ and $\mathrm{p}=0.437$, respectively (Table 2). The incidence of nausea showed a similar significant difference, with $\mathrm{p}=0.012$, but the incidence of vomiting was no different between the groups, although there was a trend (Table 2). The severity of nausea was significantly increased with increasing $\mathrm{N}_{2} \mathrm{O}$ concentration. There was no difference in the need for rescue antiemetic (Table 2), pain scores or opioids consumption between the groups (at $2 \mathrm{~h}$ and $24 \mathrm{~h}$ after surgery) (Table 3 ). 


\section{Discussion:}

This study demonstrates that $\mathrm{N}_{2} \mathrm{O}$ when administered with oxygen and sevoflurane increases the incidence of postoperative nausea. The preliminary findings indicate that $\mathrm{N}_{2} \mathrm{O}$ may increase PONV in dose/respose fashion. The inspired concentration of $70 \% \mathrm{~N}_{2} \mathrm{O}$ significantly increases the incidence of PONV at 24 hours, nausea at 24 hours and nausea VAS scores when compared with no $\mathrm{N}_{2} \mathrm{O}$. In contrast, inspired concentration of $50 \% \mathrm{~N} 2 \mathrm{O}$ did not show significant increased PONV, nor nausea at 24 hours compared with patients who received only oxygen/air.

We chose $50 \%$ and $70 \% \mathrm{~N}_{2} \mathrm{O}$ in this study because of their clinical relevance. Inspired concentrations of $\mathrm{N}_{2} \mathrm{O}$ lower than $50 \%$ are rarely used in anesthesia practice. The inspired concentration of $50 \% \mathrm{~N}_{2} \mathrm{O}$ was chosen because it is generally perceived by anesthesiologists that this concentration has minimal effect in increasing the incidence of PONV (28). However, there is no data to support that assumption. $70 \% \mathrm{~N}_{2} \mathrm{O}$ was selected as it represents the highest concentration of $\mathrm{N}_{2} \mathrm{O}$ used in clinical anesthesia practice.

All the reported studies on PONV after $\mathrm{N}_{2} \mathrm{O}$ /volatile anesthetic (enflurane or isoflurane) in gynecologic laparoscopic surgery compared a single inspired concentration of $\mathrm{N}_{2} \mathrm{O}$, usually in the range of $66 \%-70 \%$, with control $(20,21,23,24)$. The results from this study agrees with Felts et al. who demonstrated that PONV is increased from $9.3 \%$ in air/oxygen $\left(\mathrm{FI} \mathrm{O}_{2} 33 \%\right)$ to $29.2 \%$ with $66 \%$ of $\mathrm{N}_{2} \mathrm{O}$ in oxygen following enflurane anesthesia for outpatient gynecologic laparoscopy $(\mathrm{p}<0.001)$ (21). Contrary to our study, Hovorka et al. did not find significant differences in the incidence of PONV among three groups of patients anesthetized with either isoflurane or enflurane with $70 \% \mathrm{~N}_{2} \mathrm{O}$ in oxygen, and isoflurane without $\mathrm{N}_{2} \mathrm{O}$, following gynecological laparoscopy (23). This discrepancy could be explained by the different duration of the anesthesia (the mean anesthesia times among groups were 37 to 40 minutes in Hovorka's 
study and 70 to 76 minutes in our study). One of the mechanisms of $\mathrm{N}_{2} \mathrm{O}$ induced nausea and vomiting might be related to the middle ear pressure. The longer duration of $\mathrm{N}_{2} \mathrm{O}$ exposure, as in our study, likely caused a larger increase in middle ear pressure as the time to reach peak middle ear pressure is about 60 min following the introduction of $\mathrm{N}_{2} \mathrm{O}$ and about 30 minutes to return to baseline after $\mathrm{N}_{2} \mathrm{O}$ is discontinued (12). Also, in Hovorka's study smoking status was unknown which could bias the results.

Lonie et al. found significant increase only in the incidence of vomiting (from 17\% without $\mathrm{N}_{2} \mathrm{O}$ to $49 \%$ with $\mathrm{N}_{2} \mathrm{O} 67 \%$ in oxygen following enflurane anesthesia), but not nausea between groups (20). This could be due to the more frequent administration of rescue antiemetic in our study. We treated the patients with severe nausea as well as patients who vomited ( $22 \%$ of patients in the both groups with $\mathrm{N}_{2} \mathrm{O}$ and $15 \%$ in the group without $\mathrm{N}_{2} \mathrm{O}$ ). However, only a few patients were treated in Lonie's study $\left(7.5 \%\right.$ patients in $\mathrm{N}_{2} \mathrm{O}$ group and $7.1 \%$ in the group without $\mathrm{N}_{2} \mathrm{O}$ ). Sengupta et al. reported similar results as Lonie and colleagues, but the study was underpowered, with a smaller number of patients (total 64) and resulted in a non statistical difference between $\mathrm{N}_{2} \mathrm{O}$ group and oxygen group, $33 \%$ vs $12.9 \%$, respectively (24).

Recent results from the IMPACT study suggest that omitting $\mathrm{N}_{2} \mathrm{O}$ in a multimodal PONV prophylaxis strategy further decrease the incidence of PONV by about $12 \%$, if volatile anesthetic is used (29). However, the study did not address the dose response relationship of $\mathrm{N}_{2} \mathrm{O}$. The preliminary results from our study which showed that $70 \% \mathrm{~N}_{2} \mathrm{O}$ increases the incidence of nausea concur with IMPACT study and a recent meta-analysis $(10,29)$. Although our initial power analysis was expected to provide adequate power to demonstrate a dose response our actual results showed a smaller than expected difference. Assuming that this trend in the incidence of PONV at 24 hours were to persist, a study with sample size of 221 patients in each group would have been necessary to produce a statistically significant difference 
among each of three groups with a power of 0.8 and $\alpha<0.05$. Using the same assumption it would require 410 patients per group to show the significant difference in the incidence of nausea at 24 hours, and 691 patients per group for the incidence of vomiting at 24 hours. The value of this study is that it provides preliminary data that indicate that $\mathrm{N}_{2} \mathrm{O}$ may increase PONV in a dose/response fashion. We feel it would be valuable that a large prospective study should be performed to confirm if $50 \% \mathrm{~N}_{2} \mathrm{O}$ has a lower incidence of PONV than $70 \% \mathrm{~N}_{2} \mathrm{O}$.

There are several limitations to our study. It can be criticized that we should have administered a prophylactic antiemetic or combination strategy given the high risk nature of this surgical population for PONV. We however wanted to specifically investigate the dose response effect of nitrous oxide which may have been masked by the use of prophylactic antiemetics. The difference in $\mathrm{N} 2 \mathrm{O}$ concentrations between the groups also means that the FI $\mathrm{O}_{2}$ was different in G50 and G70. High FI $\mathrm{O}_{2}(0.8)$ has been shown to reduce the incidence of PONV (30,31). However, more recent studies have cast doubt on previous findings. Purhonen et al. in an ambulatory gynecological laparoscopic patients showed that supplemental oxygen does not reduce the incidence of postoperative nausea and vomiting (32). The authors compared $\mathrm{FI} \mathrm{O}_{2} 30 \%$ and $\mathrm{FI} \mathrm{O}_{2} 80 \%$ oxygen with additional $\mathrm{O}_{2}$ in PACU up to 1 hour but did not find difference in the PONV incidence after 24 hours, $62 \%$ vs 55\%, respectively. Our study had only a $20 \%$ difference in $\mathrm{FI} \mathrm{O}_{2}$ among the groups compared with $50 \%$ difference in Purhonen's study and we did not use supplemental oxygen in PACU. Therefore, the impact of oxygen in our study is likely to be small, if any. Furthermore, a recent large study involving 560 patients investigating the impact of oxygen on PONV concluded that oxygen has no impact of PONV irrespective of the site or surgery or the observational period (early or late PONV) (33).

In conclusion, we demonstrate that $70 \% \mathrm{~N}_{2} \mathrm{O}$ increases the incidence of nausea and severity of nausea at 24 hours after laparoscopic gynecological surgery in the absence of any 
prophylactic antiemetic. This preliminary findings indicate that $\mathrm{N}_{2} \mathrm{O}$ may increase PONV in dose dependent fashion. A study with sample size of $>400$ patients in each group would be necessary to produce a statistically significant difference among groups with no $\mathrm{N}_{2} \mathrm{O}, 50 \% \mathrm{~N}_{2} \mathrm{O}$ and $70 \% \mathrm{~N}_{2} \mathrm{O}$. We do not recommend using high concentration of $\mathrm{N}_{2} \mathrm{O}$ in this clinical setting. 


\section{References:}

1. Gan TJ, Franiak R, Reeves J. Ondansetron orally disintegrating tablet versus placebo for the prevention of postdischarge nausea and vomiting after ambulatory surgery. Anesth Analg 2002; 94:1199-1200.

2. Eriksson H, Korttila K. Recovery profile after desflurane with or without ondansetron compared with propofol in patients undergoing outpatient gynecological laparoscopy. Anesth Analg 1996;82:533-538.

3. Boehler M, Mitterschiffthaler G, Schlager A. Korean hand acupressure reduces postoperative nausea and vomiting after gynecological laparoscopic surgery. Anesth Analg 2002;94:872-875.

4. Scuderi PE, James RL, Harris L, Mims GR. Multimodal antiemetic management prevents early postoperative vomiting after outpatient laparoscopy. Anesth Analg 2000;91:1408-1414.

5. Scholz J, Steinfath M, Tonner PH. Postoperative nausea and vomiting [Review article]. Curr Opin Anaesthesiol 1999;12:657-661.

6. Allan BTW, Smith I. Cost considerations in the use of anaesthetic drugs. Curr Opin Anaesthesiol 2002;15:227-232.

7. Yang H, Choi PT-L, McChesney J, Buckley N. Induction with sevoflurane-remifentanil is comparable to propofol-fentanyl-rocuronium in PONV after laparoscopic surgery. Can J Anesth 2004;51:660-667.

8. Gan TJ, Meyer T, Apfel CC, Chung F, Davis PJ, Eubanks S, Kovac A, Philip BK, Sessler DI, Temo J, Tramèr MR, Watcha M. Consensus guidelines for managing postoperative nausea and vomiting. Anesth Analg 2003; 97: 62-71.

9. Michael J. Nitrous oxide: still useful in the year 2000? [Review article] Curr Opin Anaesthesiol 1999;12:461-466. 
10. Tramèr $\mathrm{M}$, Moore $\mathrm{A}, \mathrm{McQuay} \mathrm{H}$. Omitting nitrous oxide in general anaesthesia: metaanalysis of intraoperative awareness and postoperative emesis in randomized controlled trials. Br J Anaesth 1996;76:186-193.

11. Hartung J. Twenty-four of twenty-seven studies show a greater incidence of emesis associated with nitrous oxide than with alternative anesthetics. Anesth Analg 1996;83:114-116. 12. Karabiyik L, Bozkirli F, Çelebi H, Göksu N. Effect of nitrous oxide on middle ear pressure: a comparison between inhalational anaesthesia with nitrous oxide and TIVA. Eur J Anaesthesiol 1996;13:27-32.

13. Nader ND, Simpson G, Reedy RL. Middle ear pressure changes after nitrous oxide anesthesia and its effect on postoperative nausea and vomiting. Laryngoscope 2004;114:883886.

14. Orhan-Sungur M, Apfel C, Akça O. Effects of nitrous oxide on intraoperative bowel distension. Curr Opin Anaesthesiol 2005;18:620-624.

15. Pedersen FM, Wilken-Jensen C, Knudsen F, Lindekaer AL, Svare EI. The influence of nitrous oxide on recovery of bowel function after abdominal hysterectomy. Acta Anaesthesiol Scand 1993;37:692-696.

16. Akça O, Lenhardt R, Fleischmann E, Treschan T, Greif R, Fleischhackl R, Kimberger O, Kurz A, Sessler DI. Nitrous oxide increases the incidence of bowel distension in patients undergoing elective colon resection. Acta Anaesthesiol Scand 2004;48:894-898.

17. Murakawa M, Adachi T, Nakao S, Seo N, Shingu K, Mori K. Activation of the cortical and medullary dopaminergic systems by nitrous oxide in rats: a possible neurochemical basis for psychotropic effects and postanesthetic nausea and vomiting. Anesth Analg 1994;78:376-381.

18. Ohashi Y, Guo T, Orii R, Maze M, Fujinaga M. Brain stem opioidergic and GABAergic neurons mediate the antinociceptive effect of nitrous oxide in Fischer rats. Anesthesiology 2003;99:947-954. 
19. Divatia JV, Vaidya JS, Badwe RA, Hawaldar RW. Omission of nitrous oxide during anesthesia reduces the incidence of postoperative nausea and vomiting: a meta-analysis. Anesthesiology 1996;85:1055-1062.

20. Lonie DS, Harper NJ. Nitrous oxide anaesthesia and vomiting. The effect of nitrous oxide anaesthesia on the incidence of vomiting following gynaecological laparoscopy. Anaesthesia 1986;41:703-707.

21. Felts JA, Poler SM, Spitznagel EL. Nitrous oxide, nausea and vomiting after outpatient gynecologic surgery. J Clin Anesth 1990;2:168-171.

22. Chanvej L, Kijsirikul S, Thongsuksai P, Naheem L. Post-operative nausea and vomiting in out-patient gynecologic laparoscopy: a comparison of thiopental-nitrous oxide, propofolnitrous oxide and total intravenous anesthesia using propofol. J Med Assoc Thai 2001;84:697704.

23. Hovorka J, Korttila K, Erkola O. Nitrous oxide does not increase nausea and vomiting following gynaecological laparoscopy. Can J Anaesth 1989;36:145-148.

24. Sengupta P, Plantevin OM. Nitrous oxide and day-case laparoscopy: effects on nausea, vomiting and return to normal activity. Br J Anaesth 1988;60:570-573.

25. Sukhani R, Lurie J, Jabamoni R. Propofol for ambulatory gynecologic laparoscopy: does omission of nitrous oxide alter postoperative emetic sequelae and recovery? Anesth Analg $1994 ; 78: 831-835$.

26. Arellano RJ, Pole ML, Rafuse SE, Fletcher M, Saad YG, Friedlander M, Norris A, Chung FFT. Omission of nitrous oxide from a propofol-based anesthetic does not affect the recovery of women undergoing outpatient gynecologic surgery. Anesthesiology 2000;93:332-339.

27. Šimurina T, Mraović B, Sonicki Z. Incidence of PONV: Is $50 \%$ nitrous oxide friend or foe? Anesthesiology 2006;105:A1401.

28. Eger EI II. Volatile anesthetics for the new millennium. Audiodigest Anesthesiology 2000; 
$42: 15$.

29. Apfel CC, Korttila K, Abdalla M, Kerger H, Turan A, Vedder I, Zernak C, Danner K, Jokela R, Pocock SJ, Trenkler S, Kredel M, Biedler A, Sessler DI, Roewer N. A factorial trial of six interventions for the prevention of postoperative nausea and vomiting. N Engl J Med 2004;350:2441-2451.

30. Greif R, Laciny SS, Rapf B, Hickle RS, Sessler DI. Supplemental oxygen reduces the incidence of postoperative nausea and vomiting. Anesthesiology 1999;91:1246-1252.

31. Goll V, Akça O, Greif R, Freitag H, Arkilic C, Scheck T, Zoeggeler A, Kurz A, Krieger G, Lenhardt R, Sessler D. Ondansetron is no more effective than supplemental intraoperative oxygen for prevention of postoperative nausea and vomiting. Anesth Analg 2001;92:112-117.

32. Purhonen S, Turunen M, Ruohoaho U-M, Niskanen M, Hynynen M. Supplemental oxygen does not reduce the incidence of postoperative nausea and vomiting after ambulatory gynecologic laparoscopy. Anesth Analg 2003;96:91-96.

33. Turan A, Apfel CC, Kumpch M, Danzeisen O, Eberhart LHJ, Forst H, Heringhaus C, Isselhorst C, Trenkler S, Trick M, Vedder I, Kerger H. Does the efficacy of supplemental oxygen for the prevention of postoperative nausea and vomiting depend on the measured outcome, observational period or site of surgery? Anaesthesia 2006;61:628-633. 
Table 1. Patient Demographics.

$\begin{array}{ccc}\text { G0 } & \text { G50 } & \text { G70 } \\ (\mathrm{n}=46) & (\mathrm{n}=46) & (\mathrm{n}=45)\end{array}$

Age (yr)

$35.8 \pm 10.5$

$36.7 \pm 11.9$

$37.8 \pm 14.1$

Weight (kg)

$66.2 \pm 9.1$

$68.3 \pm 10.5$

$67.4 \pm 10.6$

Height $(\mathrm{cm})$

$169.9 \pm 6.9$

$168.9 \pm 5.0$

$167.9 \pm 5.7$

ASA physical status (I/II)

$36 / 10$

$35 / 11$

$35 / 10$

Smoking n (\%)

$20(43 \%)$

$17(37 \%)$

$18(40 \%)$

History of motion sickness

$16(35 \%)$

$23(50 \%)$

$16(36 \%)$

and/or PONV n (\%)

Phase of menstrual cycle (n)

Follicular/Luteal

Post-menopause

Thiopental (mg)

Duration of anesthesia (min)
$28 / 14$

4

7

10 
Duration of surgery (min)

$54.6 \pm 33.9$

$59.8 \pm 34.8$

$53.3 \pm 30.8$

Type of surgery (n)

Ovarian cystectomy/

tumorectomy

29

29

25

Myomectomy

6

7

6

Laparoscopic assisted

Vaginal hysterectomy

3

2

4

Laparoscopy for infertility

8

8

10

No statistical differences among groups $(\mathrm{G} 0=$ air, $\mathrm{G} 50=50 \%$ nitrous oxide, $\mathrm{G} 70=70 \%$ nitrous oxide).

Data presented as mean \pm SD or $n(\%)$. 
Table 2. Incidence of PONV, nausea, vomiting and use of rescue antiemetic.

\begin{tabular}{|c|c|c|c|c|}
\hline & $\begin{array}{l}\text { G0- air } \\
(n=46)\end{array}$ & $\begin{array}{c}\mathrm{G} 50-50 \% \mathrm{~N}_{2} \mathrm{O} \\
(\mathrm{n}=46)\end{array}$ & $\begin{array}{c}\mathrm{G} 70-70 \% \mathrm{~N}_{2} \mathrm{O} \\
(\mathrm{n}=45)\end{array}$ & $\mathrm{p}$ value \\
\hline PONV (24h) (n, \%) & $15(33 \%)$ & $21(46 \%)$ & $28(62 \%) \dagger$ & $0.018^{*}$ \\
\hline PONV $(0-2 \mathrm{~h})(\mathrm{n}, \%)$ & $10(22 \%)$ & $16(35 \%)$ & $20(44 \%)$ & 0.071 \\
\hline PONV (2-24h) (n, \%) & $9(20 \%)$ & $11(24 \%)$ & $14(31 \%)$ & 0.437 \\
\hline Nausea $(24 h)(n, \%)$ & $12(26 \%)$ & $16(35 \%)$ & $25(56 \%) \dagger$ & $0.012^{*}$ \\
\hline Nausea $(0-2 h)(n, \%)$ & $9(20 \%)$ & $12(26 \%)$ & $19(42 \%)$ & 0.05 \\
\hline Nausea $(2-24 h)(n, \%)$ & $6(13 \%)$ & $8(17 \%)$ & $9(20 \%)$ & 0.668 \\
\hline Nausea VAS scores (mm) & $10.9 \pm 20.5$ & $12.7 \pm 19.5$ & $20.5 \pm 21.8 \dagger$ & $0.027 *$ \\
\hline Severe nausea & $3(7 \%)$ & $3(7 \%)$ & $4(9 \%)$ & 0.882 \\
\hline Vomiting $(24 \mathrm{~h})(\mathrm{n}, \%)$ & $13(28 \%)$ & $16(35 \%)$ & $19(42 \%)$ & 0.377 \\
\hline Vomiting $(0-2 \mathrm{~h})(\mathrm{n}, \%)$ & $8(17 \%)$ & $11(24 \%)$ & $14(31 \%)$ & 0.31 \\
\hline Vomiting (2-24h) (n, \%) & $8(17 \%)$ & $9(20 \%)$ & $12(27 \%)$ & 0.527 \\
\hline $\begin{array}{l}\text { Vomiting episodes } \\
\text { in patients who vomited }\end{array}$ & $2.6 \pm 1.1$ & $2.7 \pm 2.3$ & $2.4 \pm 1.9$ & 0.463 \\
\hline Severe vomiting & $5(11 \%)$ & $6(13 \%)$ & $6(13 \%)$ & 0.926 \\
\hline Metoclopramide (n, \%) & $7(15 \%)$ & $10(22 \%)$ & $10(22 \%)$ & 0.642 \\
\hline
\end{tabular}


Data presented as mean $\pm \mathrm{SD}$.

PONV - postoperative nausea and/or vomiting

Severe nausea - VAS $>50 \mathrm{~mm}$ or duration longer than 15 minutes

Severe vomiting - 2 or more episodes of vomiting and retching within a period of $30 \mathrm{~min}$ or total number of three or more emetic episodes during $24 \mathrm{~h}$ postoperatively

* Statistically significant difference $(\mathrm{p}<0.05)$

$\dagger$ Statistically significant vs G0 $(\mathrm{p}<0.05)$ 
Table 3. Pain VAS score and opioid consumption.

$\begin{array}{cccc}\text { G0 } & \text { G50 } & \text { G70 } & \text { p value } \\ (\mathrm{n}=46) & (\mathrm{n}=46) & (\mathrm{n}=45) & \end{array}$

Pain VAS scores (mm)

$\begin{array}{rrrrr}\text { Postop at } 2 \mathrm{~h} & 21.6 \pm 13.0 & 25.4 \pm 12.9 & 23.9 \pm 15.1 & 0.30 \\ & & & & \\ 24 \mathrm{~h} & 16.8 \pm 8.5 & 13.8 \pm 11.9 & 12.6 \pm 12.3 & 0.06\end{array}$

$\begin{array}{lllll}\text { Intraoperative } & 180 \pm 70 & 190 \pm 60 & 180 \pm 80 & 0.22\end{array}$

fentanyl (mcg)

$\begin{array}{lllll}\text { Postoperative } & 6.5 \pm 22.0 & 7.1 \pm 16.4 & 10.1 \pm 19.6 & 0.27\end{array}$

meperidine $(\mathrm{mg})$

No statistical differences among groups ( $\mathrm{G} 0=$ air, $\mathrm{G} 50=50 \%$ nitrous oxide, $\mathrm{G} 70=70 \%$ nitrous oxide).

Data presented as mean \pm standard deviation. 